Campus-Level Use of Evidence: Lessons from Excellence in Assessment Designees

Jillian Kinzie and Gianina Baker

In 2016, an initiative jointly sponsored by the Voluntary System of Accountability, the Association of American Colleges \& Universities (AAC\&U), and the National Institute for Learning Outcomes Assessment (NILOA) called the Excellence in Assessment (EIA) designation, was awarded to ten institutions: Cameron University, Capella University; the Community College of Baltimore County (Sustained Excellence--demonstrating strong leadership and commitment to a culture of evidence-based decision-making centered on the use of campus-level assessment results. Sustained Excellence acknowledges institutions that have maintained a solid foundation and track record of integration of assessment data from across campus and used assessment results to guide campus programs and curriculum for a period of five or more years.); Indiana University-Purdue University Indianapolis (Sustained Excellence); Kansas State University (Sustained Excellence); Mills College; Mount St. Joseph University; the Rose-Hulman Institute of Technology (Sustained Excellence); the University of WisconsinMadison; and Zayed University. Five institutions-James Madison University (Sustained Excellence); Bowling Green State University; the Middlesex Community College; Rio Salado College; and Southern Connecticut State University joined in 2017 as EIA designees.

EIA designated institutions are models of exemplary assessment practice. They offer examples of a range of innovative approaches to assessment and provide inspiration to others doing good work. Reflecting on two years of EIA awards and reviews involving applications from 47 institutions, this article highlights observations about one particular dimension of the EIA designation: the use of evidence of student learning.

\title{
Campus-level Use of Evidence
}

The Excellence in Assessment (EIA) designation recognizes exemplary efforts across the six components of NILOA's Transparency Framework including the explicit specification of learning outcomes; plans for gathering evidence; training and resources provided to faculty and staff to help them understand, develop, implement, communicate, and use evidence; information on assessment activities underway; results from assessment; and the use of evidence to improve student learning. Expectations for excellence in these six components, and two additional elements encompassing the diversity of groups and individuals engaged in assessment activities and growth and improvement plans, are spelled out for applicants and reviewers in the EIA evaluation rubric (www.learningoutcomesassessment.org/eiadesignation.html). Although EIA applicants must demonstrate the strengths of their campus-level assessment plan and activities as well as areas for growth and improvement on all eight domains, one dimension-Use of Campuslevel Evidence of Student Learning-surfaced as the component where we saw some of the greatest range of excellence in practice.

NILOA's Transparency Framework provides expectations for the use of evidence of student learning. It emphasizes specific uses for evidence, including the extent to which evidence of student learning informs problem identification, decision-making, planning, goal setting, faculty development, program review, course revision, and other accountability and performance 
improvement initiatives. In addition, the framework reflects that the transparent use of evidence involves the communication of evidence to particular audiences including faculty, staff, administrators, students, governing boards, employers, and others to facilitate the use of assessment results to identify areas where changes in policies and practices can lead to improvement. These specifications are reflected in the EIA rubric in four dimensions with associated standards for excellence (see Figure 1).

Figure 1. EIA 2017 Evaluation Rubric: Use of Campus-level Evidence of Student Learning

\begin{tabular}{|l|l|}
\hline \multicolumn{1}{|c|}{ Dimension } & \multicolumn{1}{c|}{ Standard for Excellence } \\
\hline $\begin{array}{l}\text { Integration of campus-level } \\
\text { results with measures used at } \\
\text { other levels to guide campus } \\
\text { decision-making }\end{array}$ & $\begin{array}{l}\text { Campus-level assessment results have been considered } \\
\text { in combination with assessment results at other levels of } \\
\text { the institution to guide decision-making related to } \\
\text { changes in policies and practices that may lead to } \\
\text { improved student learning. }\end{array}$ \\
\hline $\begin{array}{l}\text { Evidence of use of assessment } \\
\text { results from all levels of campus } \\
\text { provided to stakeholders }\end{array}$ & $\begin{array}{l}\text { Stakeholders from both inside and outside the } \\
\text { institution are regularly provided with evidence that } \\
\text { institutional decision-making is appropriately guided by } \\
\text { assessment results from multiple levels of campus } \\
\text { assessment. }\end{array}$ \\
\hline $\begin{array}{l}\text { Communication of changes made } \\
\text { as a result of assessment evidence } \\
\text { from all levels of campus }\end{array}$ & $\begin{array}{l}\text { Changes made as a result of assessment are } \\
\text { communicated to both internal and external campus } \\
\text { audiences, including students. Communications include } \\
\text { information on evidence supporting the need for } \\
\text { change. }\end{array}$ \\
\hline $\begin{array}{l}\text { Communication of outcomes from } \\
\text { changes made as a result of } \\
\text { assessment evidence from all } \\
\text { levels of campus }\end{array}$ & $\begin{array}{l}\text { Changes made as a result of assessment are monitored } \\
\text { and evaluated. Outcomes from changes are } \\
\text { communicated to both internal and external campus } \\
\text { audiences, including students. Communications include } \\
\text { information on evidence used to evaluate the change. }\end{array}$ \\
\hline
\end{tabular}

What makes the Use of Campus-level Evidence of Student Learning criteria the most challenging to demonstrate? Is it that institutions are inexperienced using evidence or lack structured means and systems for integrating data into decision-making processes? Is it that communication about assessment use is not routine, or systems are not in place to monitor changes? Perhaps this is further confirmation of the need that Blaich and Wise (2011) identified for systematic training for campus assessment leaders in political skills and organizational knowledge to more fully utilize their assessment data across campuses.

EIA designated institutions provided several examples representing the effective use of evidence. For instance, James Madison University's laser focus on assessment for improvement is widely promoted and practiced in its "weigh pig, feed pig, weigh pig" approach to improvement (Fulcher, et al. 2014). The institution is also transparent about evidence of student growth in each of its five general education learning clusters and has widely shared results and what they mean for instructional practice and student learning. Rio Salado College demonstrated exceptional use of evidence as an outcome of its campus-wide Total Quality Management PlanDo-Check-Act (PDCA) cycle. The institution's home-grown Assessment Data Display supports 
efforts to make evidence of campus-level learning transparent and assessment results are wellintegrated into its strategic plan. Southern Connecticut State University used evidence in the compilation and use of data from multiple sources, and the implementation of longitudinal studies of student achievement and success to develop a picture of student learning to inform their student success initiatives. Overall, EIA designees are institutions that prioritize improvement of student learning and use assessment evidence to guide and monitor their actions.

Yet, the use of evidence was the dimension most frequently noted by reviewers (and also candidly discussed by institutions themselves) as an area for improvement across all 47 EIA applications. For example, even campuses that implemented comprehensive assessment processes that engaged many stakeholders to help make sense of the data were less deliberate in following up on the impact of this approach and what it ultimately influenced. Institutions distinguished for a wealth of data only had plans for how those data would be used to improve practice. Campuses with well-established program review processes and strong communication outlets for assessment results fell short in terms of demonstrating how evidence was being used at program and institution-levels. Many campuses represented their intentions for assessment to inform plans for improvement, but few had evidence to show the degree to which assessment results were used.

The observation that the quality of excellence in using evidence varied across applications might not be surprising given reports that few institutions successfully "close the loop" (Banta \& Blaich 2011) and the conclusion that compliance, rather than improvement, is driving campus assessment practice (Kuh, et al. 2015; NILOA 2016). Although greater proportions of institutions are reporting the use of evidence to improve undergraduate education (Kuh, et al. 2015), the challenge appears to be that most institutions are at a nascent level of demonstrating transparency and evidence use.

The 15 EIA recognized institutions provide instructive models through implementation of custom-designed approaches to encourage and communicate the use of evidence in their assessment practice. Campuses seeking to enhance their use of evidence might emulate the EIA designees. However, what might be more helpful is for campuses to conduct their own self-study using the EIA evaluation rubric criteria for use of evidence. In fact, many institutions have reported the use of the EIA evaluation rubric and application materials as a means to examine institutional readiness to apply for a designation or to review current campus-level assessment processes, and Robinson, Demeter, Frederick and Sanders (2017) explain their use of the rubric to conduct a gap analysis between the standards of excellence and their current assessment practices. Even more, institutions are urged to redouble their efforts to focus on their most potentially actionable evidence, that which addresses the questions posed by people who can change policies and pedagogical practices. Enhancements to the use and communication of assessment results should follow when assessment addresses genuine campus questions.

Observations from EIA applications affirm that using student learning evidence to make informed decisions that enhance educational quality is not easy. EIA designees offer promising examples of campuses that prioritize gathering evidence and putting it to use, and the EIA rubric provides a standard for institutions to assess their practice. Yet, it's clear: colleges and 
universities must make better use of student learning evidence that will, in turn, generate action to improve student learning and educational quality.

\section{References}

Banta, T. W., and C. F. Blaich. 2011. Closing the Assessment Loop. Change, 43(1), 22-27.

Blaich, C. F., and K. S. Wise. 2011, January. From Gathering to Using Assessment Results: Lessons from the Wabash National Study (NILOA Occasional Paper No. 8). Urbana, IL: University of Illinois and Indiana University, National Institute for Learning Outcomes Assessment.

Fulcher, K. H., M. R. Good, C. M. Coleman, and K. L. Smith. 2014, December. A Simple Model for Learning Improvement: Weigh Pig, Feed Pig, Weigh Pig (Occasional Paper No. 23). Urbana, IL: University of Illinois and Indiana University, National Institute for Learning Outcomes Assessment.

Kuh, G. D., S. O. Ikenberry, N. A. Jankowski, T. R. Cain, P. Ewell, P. Hutchings, and J. Kinzie. 2015. Using Evidence of Student Learning to Improve Higher Education. San Francisco, CA: Jossey-Bass.

National Institute for Learning Outcomes Assessment. 2016, May. Higher Education Quality: Why Documenting Learning Matters. Urbana, IL: University of Illinois and Indiana University, Author.

Robinson C., E. Demeter, J. G. Frederick, and C. Sanders. 2017. When the Call Comes, Keep Calm and Assess on: Using the EIA Designation Rubric as a Self-study for Improvement. (NILOA Assessment in Practice). Retrieved from: http://www.learningoutcomeassessment.org/documents/AssessmentInPractice_EIA_UNC.pdf.

Jillian Kinzie is associate director in the Center for Postsecondary Research and National Survey of Student Engagement Institute in the School of Education at Indiana University. Gianina Baker is assistant director of National Institute for Learning Outcomes Assessment (NILOA) at the University of Illinois Urbana-Champaign College of Education. 